\title{
TWO CASES OF BRONCHIOGENIC CYST ASSOCIATED WITH ANOMALOUS ARTERIES ARISING FROM THE THORACIC AORTA
}

\author{
BY \\ E. TOSATTI AND J. A. GRAVEL \\ From the Surgical Department and the Pathological Institute, Sabbatsbergs Hospital, \\ Stockholm
}

(RECEIVED FOR PUBLICATION OCTOBER 16, 1950)

Two cases of congenital bronchiogenic cyst, in which an anomalous artery arose from the thoracic aorta and reached the cystic area of the affected lobe, were operated upon at Sabbatsbergs Hospital, Stockholm. The operations took place between July, 1947, and May, 1949.

\section{CASE Reports}

Case No. 1.-E. M., 23 years old, had a history of intermittent bronchitic attacks during the past 17 years, with variable amounts of sputum and a reduced vital capacity. The general condition was good. There was no clubbing of the fingers. The radiographs showed a thin-walled calcified cyst, in which there was a fluid level, situated in the right inferior lobe (Fig. 1).

Lobectomy was performed by Professor C. Crafoord on May 23, 1949, when an abnormal artery was found arising from the aorta just above the diaphragm, close to the pulmonary ligament, and entering the base of the lung.

A cyst, the size of a little orange communicating with several other smaller surrounding cysts, was found in the apical segment of the lower lobe (Fig. 2). The cystic area communicated with the bronchial tree. There were no anomalies in the branches of the pulmonary artery, but an artery of a diameter of 5 or $6 \mathrm{~mm}$. was found entering the cystic portion of the lobe (Fig. 3) ; its distribution appeared to be limited to this area. This artery, as was seen pre-operatively, arose from the thoracic aorta.

By digestion with concentrated hydrochloric acid, it has been possible to demonstrate the presence of a large anastomosis (Fig. 4) in the operation specimen between the branches of the anomalous vessel and those of the pulmonary artery.

The respiratory epithelium lining the surface of the cysts showed polymorphism; it was papillary in some areas, and adenomatous in others. Deep to the epithelium cartilage, glands, muscular cells, elastic fibres, and a few areas of small cell infiltration were found. Small cysts were found in the surrounding pulmonary tissue, and there were two minute fibrous tubercles in the posterior basal segment of the lobe.

The anomalous artery and its branches were of normal structure, and showed no signs of atheromatous degeneration. Apart from the fact that presumably they carried oxygenated blood, and were not accompanied by a bronchial artery, the greater thickness of their walls was the only structural difference between them and branches of the pulmonary artery. Figs. 5-7 illustrate the structure of the anomalous artery, and the histology of the cysts. 

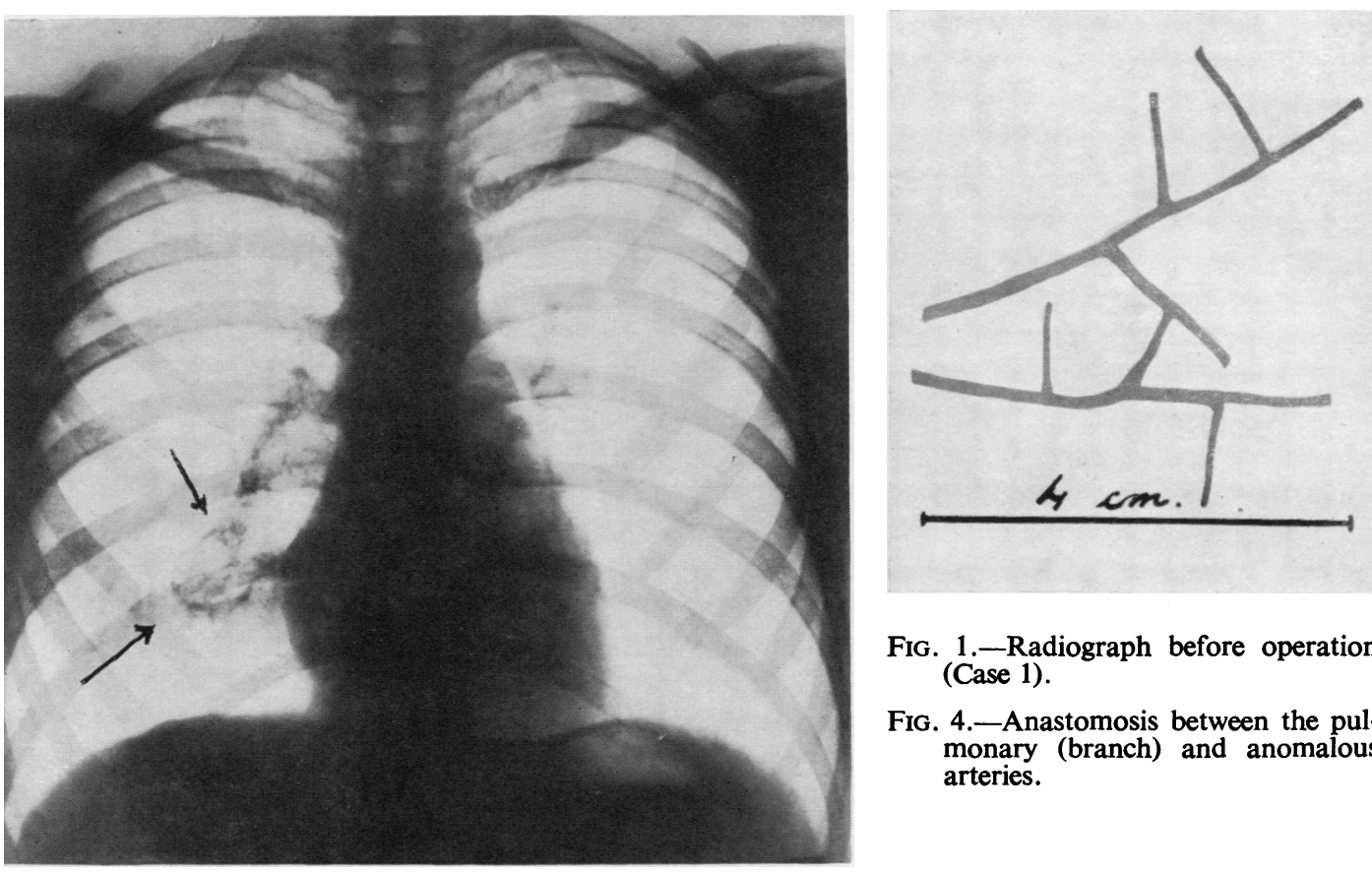

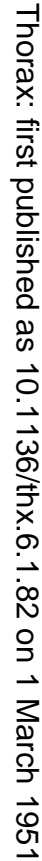

Fig. 1.-Radiograph before operation (Case 1).

Fig. 4.-Anastomosis between the pulmonary (branch) and anomalous arteries.
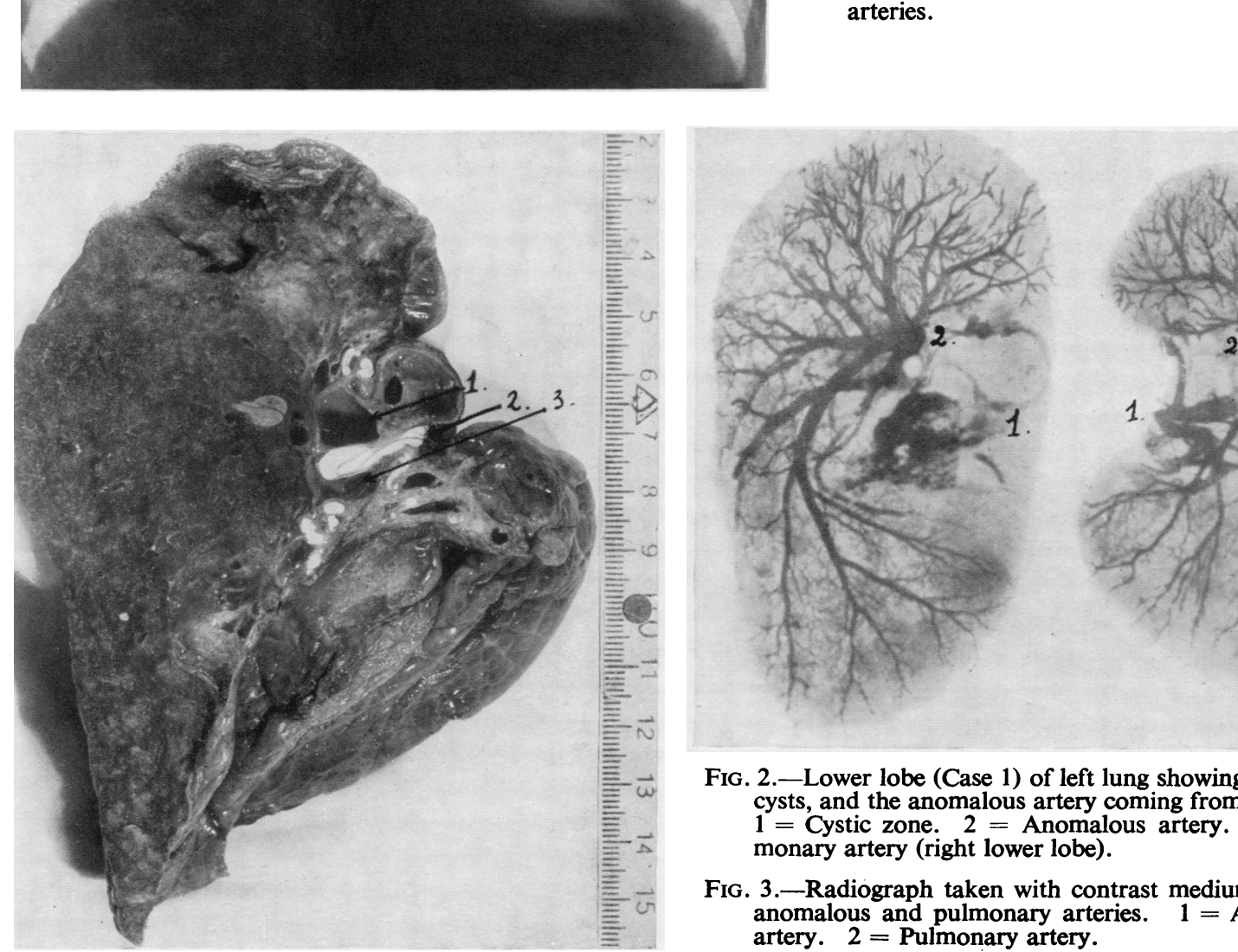

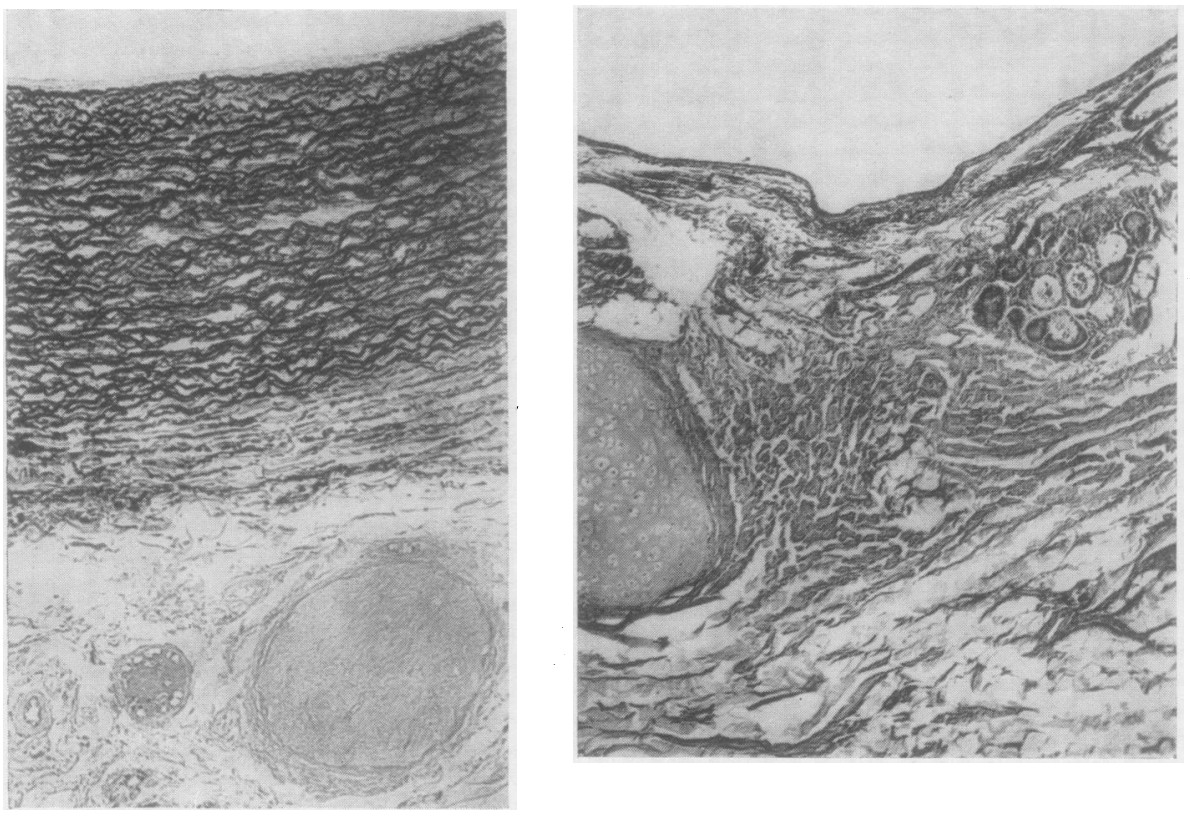

Fig. 5.-Section of anomalous artery showing elastic structure.

Fig. 6.-Wall of the biggest cyst showing glands, cartilage, and elastic fibres under the epithelium.

FIG. 7.-Papillary aspect of the epithelium in one of the bigger cysts.

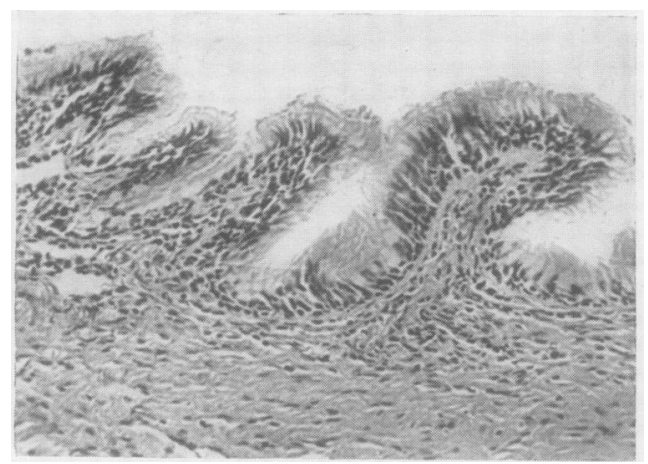

Case No. 2.-P. B. O., a boy, 5 years of age, had a two-year history of illness beginning with an empyema; this was drained. His general condition was poor. There was no clubbing of the fingers. A radiograph revealed some cysts of the left lower lobe. At operation, a lobectomy performed by Professor Crafoord, a large artery containing much elastic tissue was found $2-3 \mathrm{~cm}$. above the diaphragm; it arose from the thoracic aorta and entered the base of the lung (Fig. 8).

A system of intercommunicating cavities as large as a walnut was found ; these at one point were in connexion with the basal bronchi. There was chronic inflammation in the apical segment of the lower lobe. The demarcation between the cystic zone and the normal lung was not sharply defined. A vessel $(4 \mathrm{~mm}$. in diameter) entered the medial superior part of the lobe, and, after running vertically for 3 to $4 \mathrm{~cm}$., branched out of the cystic area and on to the adjacent pulmonary tissue.

The walls of the cysts were lined with a respiratory epithelium, under which cartilage, glands, elastic fibres, and muscular cells were found. Some small cysts were observed 
in the surrounding pulmonary tissue. The anoma!ous artery was identical in structure with the artery of the preceding case.

\section{Discussion}

The literature concerning bronchogenic cysts of the lung may be divided into three periods: (1) the first description, three centuries ago, by Fontanus and Nonnus, quoted by Rizzi and de Lorenzi (1948); (2) the classical anatomo-pathological studies by Grawitz, Altmann, Müller, from 1880 to 1928 (quoted by Biocca); (3) the most recent clinical and radiological studies, which have resulted in the differentiation of bronchogenic cysts from conditions such as other types of cyst, polycystic lungs, intra- and extra-sequestration of cystic lung, bronchiectasis, and emphysema.

The pathogenetic problem, illustrated by our cases, has not been completely elucidated, but we feel that it cannot be dealt with without briefly recalling some points of pulmonary embryology. At the end of the fifth week of embryonic life, the laryngotracheal channel appears on

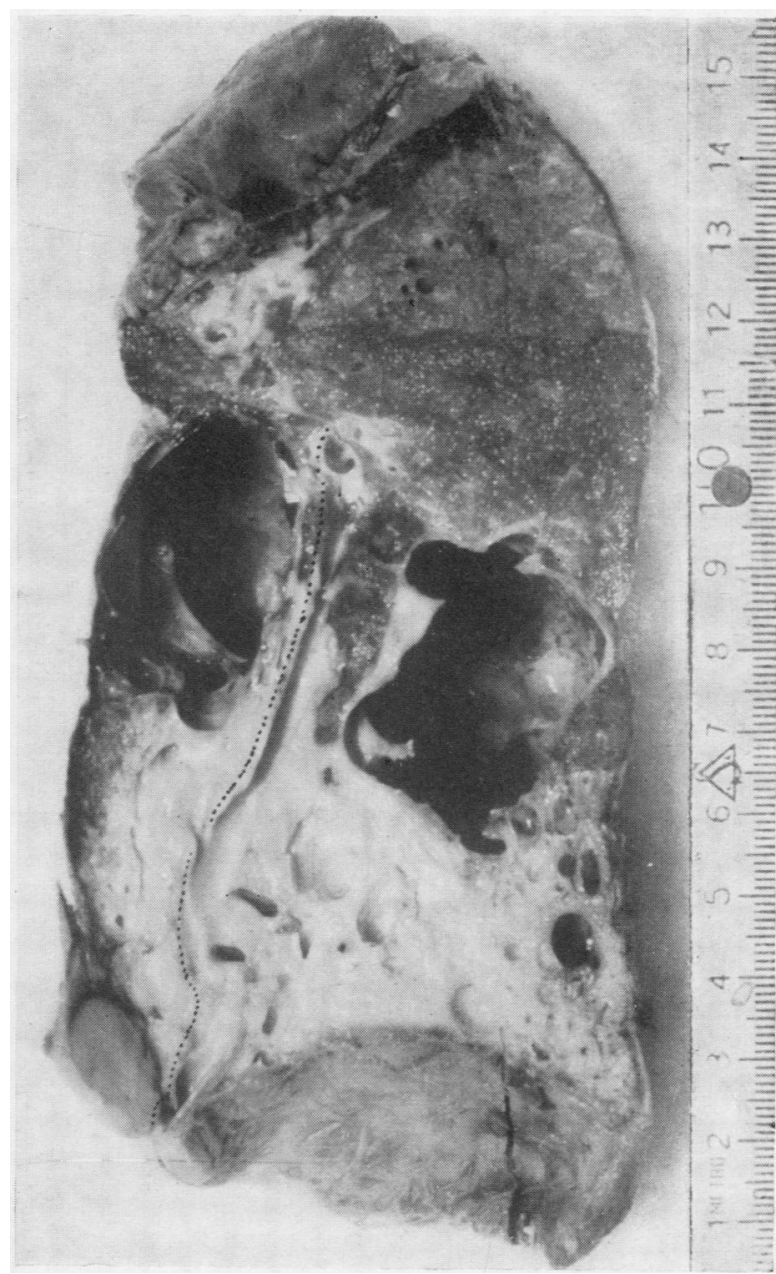

FIG. 8.- Lower lobe of the right lung (Case 2), showing the system of cysts, the anomalous artery coming from the aorta, and the branch of the pulmonary artery.

the ventral surface of the cephalic fore-gut. From its caudal extremity two bulbous tips protrude during the seventh week. These buds later divide in two on the left side and three on the right. The complete bronchial tree is the result of the division and canalization of these buds.

On the other hand, the development of the pulmonary parenchyma takes place in four phases as described by Kolliker (quoted by Biocca); namely the growth of small primitive pulmonary glands in grape form, followed by infundibules, alveolar explosions, and the final formation of the intra-alveolar walls.

According to Huntington (1919), Evans (1909), and Harris and Lewis (1940), in the early embryo the vascular system is represented by a capillary plexus 
(area vasculosa) which envelops the fore-gut. Subsequently, some of the ventral channels of this plexus enlarge and give rise to the pulmonary arteries. The normal embryonic shift disrupts the dorsal connexions of these vascular channels and usually only leaves those destined to become the bronchial arteries. If other dorsal channels persist they account for the presence of anomalous arteries in postnatal life.

The interdependence of these two circulatory systems in the lung (pulmonary and aortic) has been known since the times of Valsalva. Anastomoses between the two systems have been described in various diseases such as bronchiectasis, emphysema, tuberculosis, abscess of the lung, and in mitral stenosis (Liebow, Hales, and Lindskog, 1949 ; Wood, Sellors, Roberts, Edwards, Scadding, and Ellman, 1940). It has also been known for more than a century that such anastomoses occur in amphibians and reptiles, especially in snakes. Cases of persistence in man of the dorsal vessels, represented by anomalous arteries from the aorta, have been described by Huber (1777), Maugars (1902), Meckel (1820), Hyrtl (1839), and more recently by Park (1912), Batts (1939), Harris and Lewis (1940), Davies and Gunz (1944), and Pryce (1946). In two cases (Maugars's and Batts's) the artery arose from the abdominal aorta, emerging through the diaphragm. In the other cases it arose from the thoracic aorta, above the diaphragm, at the level of the pulmonary ligament. Eppinger and Schauenstein (1902) referred to an anomalous vessel running from the phrenic artery to the lung. McCotter (1910) describes such vessels running from the intercostal arteries and Meckel those from the subclavian artery. Atheromatous changes were often found in these arteries, and sometimes the lung they supplied was normal, but usually it showed pathological changes. Pryce described seven cases of sequestration of the lung in which there was an artery running from the aorta to the diseased part of the lung.

Three cases of cystic changes in the lung, with an arterial supply similar to that in our cases, have been observed by Hinson (personal communication).

Among the various theories on the pathogenesis of pulmonary cysts and sequestration of the lung, two, in our opinion, deserve special attention. The first implies an anomaly in the development of the lung buds, either through failure to divide or lack of canalization. The second suggests that the formation of pulmonary cysts depends on a congenital or acquired alteration of the lung circulation. Either mechanical effects, such as pressure of the anomalous artery, would cause the cyst, or else this vessel, being abnormal, might hamper the proper circulation of the lung, with subsequent cystic degeneration. Both theories may be combined to explain ectopic intra- and extra-lobar lungs, in which a cystic, bronchopulmonary mass is dissociated from the normal bronchial tree and included (intralobar sequestration) or not (extralobar sequestration) within a pulmonary lobe. Some surmise that the lung sequestration is due to the detachment and inclusion into the surrounding tissue of the bulbous tip of the bronchial tree, at one stage or other of its development. This detachment would be caused by the traction exerted by an. anomalous artery anchored on one side to the aorta, and branching off to supply a limited area of the lung.

In addition to the arterial anomalies which were found, our two cases of congenital bronchogenic cysts of the lung had other interesting features. In both cases, there were a remarkable number of smaller cysts in the lung tissue surrounding the larger cystic area. This was sufficiently marked to give the impression of 
emphysema. Histologically, one case was remarkable for the polymorphism of its epithelium (sometimes papillary, sometimes adenomatous), while the other exhibited a notable richness of cartilage. Radiologically, one case presented a cystic wall sufficiently radio-opaque to convey the belief that it was calcified, a very rare occurrence according to Stewart, Tendeloo, Villaret, and Waldenburg (quoted by Rizzi and de Lorenzi, 1948).

Clinically, in neither case was haemoptysis present, although it is believed to be the rule in such conditions. In one there was associated pulmonary tuberculosis, a rare occurrence according to Biocca (1947). In the other case an empyema complicated the picture; it is well known that suppuration and acute distension of the cyst are frequent complications, but, according to Schenck (1937), an empyema is rare. Both cases needed a lobectomy, and in each the technical difficulties of the operations were increased by the anomalous vessels.

The blood supply to congenital cystic areas of the lung has been the subject of many investigations. The older works mentioned the red wine colour of the cystic walls: but more recent papers tell of ischaemia (Eberth, quoted by Rizzi and de Lorenzi ; Morelli, 1935), of endovasculitis obliterans (Rindfleisch, quoted by Rizzi and de Lorenzi, 1948), of telangiectases of small aneurysms (Bayer, quoted by Rizzi and de Lorenzi), and of endothelial modifications (De Nicola, 1946). That congenital malformations of the vessels of the nervous system and of various other organs may be associated with bronchogenic cysts of the lung was first stated by Schenck (1937) and Villaret and co-workers (quoted by Rizzi and de Lorenzi). Congenital anomalies of the blood supply to the entire lung in cases of bronchogenic cysts have been described. Lotzin (quoted by Rizzi and de Lorenzi) and Sauerbruch (1939) have reported anomalies of Cuvier's ductus, Gravinghoff and Dardenne (quoted by Rizzi and de Lorenzi) anomalies in the size and location of the pulmonary artery, and Müller (1928) anomalies of the azygos vein. Congenital anomalies (size, location) of the vessels normally reaching the pulmonary cystic area were reported by Laennec, Forlanini, Waldenburg, and more recently by Tendeloo (quoted by Rizzi and de Lorenzi), who attributed the presence of the bronchogenic cyst to an anomaly in the local blood supply. The importance of the works by Müller, Haight (1942), and Pryce, so far as this study is concerned, cannot be overlooked.

We submit that the only difference between the bronchogenic cyst and the intralobar sequestration of a cystic lung lies in the fact that the former communicates with the normal bronchial tree, while the latter appears to be separated from it.

Aetiologically, our cases can be analysed together, because of their similarity. In both, an anomalous artery arose from the thoracic aorta and reached the cystic area of a lower pulmonary lobe ; in one it anastomosed with branches of the pulmonary artery. It does not seem probable to us that the anomalous artery had nothing to do with the pulmonary malformation. But why should the vessel in both cases be directed only towards the cystic tissue ? It seems unlikely that the pulmonary malformation, if it existed beforehand, could have caused the growth of the anomalous vessel. At most, one can say that the inflammatory process around the cystic area may have caused an increase in the size of the artery. We do not believe that the anomalous artery could have persisted simply to supply a supernumerary cystic lobe, or that the anomalous artery could have caused ectopia of 
a bronchopulmonary mass, since the cystic zone was not detached from the bronchial tree. It is possible that the anomalous artery supplied normal pulmonary tissue which developed secondary cystic changes from other causes. In favour of this idea is the fact that one often sees anomalous arteries running to normal pulmonary tissue.

In our opinion, it is more probable that the cystic changes in the lung and the anomalous blood supply are caused by a common embryonic malformation. We believe that the cysts of the lung are caused by an anomaly of the lung-bud division and that the anomalous artery supplying this part may persist.

\section{Summary}

Two cases of bronchogenic cyst of the lung associated with an anomalous artery arising from the thoracic aorta are discussed. Reference is made to the pathogenesis of this double anomaly, and mention is made of its importance during lobectomy.

We should like to thank Professor Crafoord for his kind hospitality, and for affording us the opportunity of studying the two cases operated on by him. We are also indebted to Dr. A. Bergstrand for his helpful interest and valuable suggestions.

Batts, M.,jun. (1939). J. thorac. Surg., 8, 565.

\section{REFERENCES}

Bayer. Quoted by Rizzi and de Lorenzi.

Biocca, P. (1947). Arch. Chir. Torace, 1, 191.

Davies, D. V., and Gunz, F. W. (1944). J. Path. Bact., 56, 417.

De Nicola, P. (1946). Arch. ital. Anat. Istol. patol., 19, 3.

Eberth. Quoted by Rizzi and de Lorenzi.

Eppinger, H., and Schauenstein, W. (1902). Ergebn. allg. Path. path. Anat., vol. 1, 8, 267.

Evans, H. M. (1909). Anat. Rec., 3, 498.

Fontanus and Nonnus. Quoted by Rizzi and de Lorenzi.

Gravinghoff and Dardenne. Quoted by Rizzi and de Lorenzi.

Grawitz, Altmann, and Müller. Quoted by Biocca.

Haight, C. (1942). J. thorac. Surg., 11, 630.

Harris, H. A., and Lewis, I. (1940). Ibid., 9, 666.

Hinson, K. F. W. Personal communication.

Huber, J. J. (1777). Acta Helvet., 8, 85.

Huntington, G. S. (1919). Anat. Rec., 17, 165.

Hyrtl, J. (1839). Med. Jb. öst. St., 18, 3.

Kolliker. Quoted by Biocca.

Laennec, Forlanini, Waldenburg, and Tendeloo. Quoted by Rizzi and de Lorenzi.

Liebow, A. A., Hales, M. R., and Lindskog, G. E. (1949). Amer. J. Path., 25, 211.

Lotzin. Quoted by Rizzi and de Lorenzi.

McCotter, R. E. (1910). Anat. Rec., 4, 291.

Maugars, A. (1902). J. Méd., 3, 452 .

Meckel, J. F. (1820). Dtsch. Arch. Physiol., 6, 453.

Morelli, M. (1935). Arch. ital. Anat. Istol. patol., 6, 228.

Müller, H. (1928). In Henke and Lubarsch's Handbuch der speziellen pathologischen Anatomie und Histologie, vol. 3, pt. 1, p. 577. Berlin.

Park, E. A. (1912). Proc. N.Y. path. Soc., n.s., 12, 88.

Pryce, D. M. (1946). J. Path. Bact., 58, 457.

Rindfleisch. Quoted by Rizzi and de Lorenzi.

Rizzi, G., and de Lorenzi, O. (1948). Cisti e pseudocisti del polmone. Faenza.

Sauerbruch, F. (1939). 11 Congr. Soc. int. Chir., Bruxelles, vol. 2, p. 261.

Schenck, S. G. (1937). Arch. intern. Med., 60, 1 .

Stewart, Tendeloo, Villaret and Coll., and Waldenburg. Quoted by Rizzi and de Lorenzi.

Villaret and co-workers. Quoted by Rizzi and de Lorenzi.
Wood, W. B., Sellors, H., Roberts, J. E. H., Edwards, T., Scadding, J. G., and Ellman, P. (1940). Proc. roy. Soc. Med., 33, 335. 